\title{
Qualidade de flores de girassóis ornamentais irrigados com águas residuária e de abastecimento
}

\author{
Quality the ornamental sunflowers irrigated with waste and supply waters \\ Leandro Oliveira de Andrade ${ }^{1}$, Hans Raj Gheyi ${ }^{2}$, Reginaldo Gomes Nobre ${ }^{3}$, Nildo da Silva Dias ${ }^{4}$, \\ Elka Costa Santos Nascimento 5
}

\begin{abstract}
RESUMO
O uso de água residuária tratada vem sendo praticado na atividade agrícola e tende a ser uma alternativa econômica e ambiental para o cultivo de flores, principalmente de corte, em que o produto final não tem contato direto com a água. Objetivou-se avaliar a qualidade de flores de genótipos de girassol para corte irrigados com águas residuária e de abastecimento em sistema orgânico de cultivo. $\mathrm{O}$ ensaio foi conduzido em ambiente protegido pertencente à Universidade Federal de Campina Grande - PB, Brasil, adotando-se o delineamento experimental de blocos casualizados em esquema fatorial 4 x 2, com 3 repetições e 2 plantas por parcela, sendo 4 genótipos de girassol (EMBRAPA 122/V2000 - $\mathrm{G}_{1}$, Sol Noturno $-\mathrm{G}_{2}$, Sol Vermelho $-\mathrm{G}_{3}$ e Debilis Creme $-\mathrm{G}_{4}$ ), combinadas com 2 águas de irrigação (água de abastecimento $-\mathrm{A}_{1}$ e água residuária tratada oriunda de esgoto doméstico tratado $-\mathrm{A}_{2}$ ). A prática do reúso se mostrou significativamente melhor para as variáveis de altura de planta, diâmetro de caule, número de folhas, diâmetros externo e interno de capítulo, além de número de pétalas. O melhor genótipo, de maneira geral, foi o Sol Noturno, que se destacou sobremaneira no período pós-colheita, com o melhor resultado de durabilidade.
\end{abstract}

Palavras-chave: Helianthus annuus L., flores de corte, reúso de água.

\section{ABSTRACT}

The use of treated wastewater is being practiced in agriculture and tends to be an economical and environmental alternative for flower cultivation, especially for cut flowers, as the final product has no direct contact with the water. The objective of this research was to evaluate the use of this alternative source of irrigation water on the growth of cut sunflower genotypes under an organic system. The trial was carried out in a greenhouse at Universidade Federal de Campina Grande - PB, Brazil, adopting a randomized block design in a $4 \times 2$ factorial with three replicates and two plants per plot, with 4 genotypes of sunflower (Helianthus annuus L.) (EMBRAPA V2000/122 - $G_{l}$, Sol Noturno $-G_{2}$, Sol Vermelho $-G_{3}$ and Debiblis Crème $-G_{4}$ ) combined with 2 irrigation treatments (municipal supply water $-A_{1}$ and treated sewage wastewater $-A_{2}$ ). The treated wastewater was significantly better for the variables plant height, stem diameter, leaf number, external and internal diameter of the capitulum, as well as number of petals. In general the best genotype was Sol Noturno, which stood out particularly after harvest, with the best result for durability.

Key words: Helianthus annuus $L$., cut flowers, water reuse.

\section{Introdução}

No setor do agronegócio brasileiro, a produção de flores e plantas ornamentais é uma atividade consolidada e que já alcançou grande importância econômica em vários estados brasileiros. A expansão no mercado de flores é um elemento vital para a sobrevivência e para o desenvolvimento do complexo agroindustrial de flores, ampliando a demanda pelos produtos ofertados e garantindo um faturamento

1 Engenheiro Agrônomo - Doutor em Engenharia Agrícola - Universidade Estadual da Paraíba /UEPB - Campus II, Lagoa Seca, Paraíba, PB - leandro.agroecologia@gmail.com

2 Engenheiro Agrônomo - Doutor - Núcleo de Engenharia de Água e Solo /NEAS - Universidade Federal do Recôncavo da Bahia/UFRB - CEP 44380-000 - Cruz das Almas, BA - hans@pq.cnpq.br

3 Engenheiro Agrônomo - Doutor - Unidade Acadêmica de Ciências Agrárias - Universidade Federal da Paraíba/UFCG - CP 137, CEP 58.840-000 - Pombal, PB - rgomesnobre@pq.cnpq.br

4 Engenheiro Agrônomo - Doutor - Departamento de ciências ambientais/DCA - Universidade Federal Rural do Semi-Árido/ UFERSA - CP 137, CEP 59625-900 - Mossoró, RN - nildo@ufersa.edu..br

5 Unidade Acadêmica de Engenharia Agrícola, UFCG - Campina Grande-PB - elka.costa@ hotmail 
anual capaz de sustentar seu crescimento e geração de emprego (Lins; Coelho, 2004). Para Bongers (1995), a floricultura é particularmente interessante para os pequenos agricultores, pois representa uma fonte de receita significativa, e pode gerar 15 a 20 empregos por hectare, com faturamento superior ao de outras culturas, como o arroz ou feijão.

Beneficiando também a mão-de-obra empregada em atividades agrícolas, apareceu há alguns anos a filosofia da agricultura ecologicamente correta que é o sistema de produção agrícola que exclui o uso de produtos químicos sintéticos, objetivando minimizar os impactos negativos causados ao ambiente, biodiversidade do solo; podendo ser tão rentável quanto o sistema convencional (Mäder $e t$ al., 2002).

O uso agrícola de esgotos e biossólidos (lodo originado em estação de tratamento de esgoto sanitário, que passou por tratamento biológico) cresceram, acentuadamente, em todo o mundo, particularmente em regiões áridas e semiáridas de países em desenvolvimento, como resposta à necessidade de aumentar a produção agrícola, principalmente de alimentos, sem aplicação de fertilizantes sintéticos; então vale a ressalva de que as águas residuárias, assim como o lôdo de esgoto não são considerada fertilizante químico (Polat $e t$ al., 2010). O efluente tratado, quando utilizado como biofertilizante, possui notadamente valorização econômica; além de benefícios ambientais, pois a prática de reúso remove parcial ou totalmente o teor de nutrientes contido nos efluentes como, principalmente nitrogênio e fósforo, antes do seu despejo nos corpos d'água, impedindo a eutrofização dos mananciais.

A cultura do girassol é bastante valorizada e difundida por se tratar de uma fonte rica em óleo, extraída de sua semente, para a produção melífera e também por ser utilizada como fonte de farelo ou mesmo silagem para a alimentação animal. Sua beleza é muito apreciada, tendo grande valor estético como planta ornamental, e pode ser cultivada para a produção de flores de corte e de vaso (Schoellhorn et al., 2003). O desenvolvimento de variedades com porte baixo e cores variadas, permitiu que esta planta passasse a figurar em arranjos e decorações. Seu formato exótico e o tom amarelo alaranjado intenso de suas flores acrescentam vida e dinamismo aos ambientes.

Tendo em vista o potencial hídrico e nutricional das águas de esgoto doméstico e a sua utilização em culturas ornamentais com menor risco de contaminação ambiental, este trabalho tem como objetivo avaliar a qualidade de flores de genótipos de girassol para corte irrigadas com água residuária tratada e de abastecimento em sistema orgânico de cultivo.

\section{Material e Métodos}

O ensaio foi conduzido no período de 27 de janeiro a 21 de abril de 2010, em casa de vegetação do tipo capela, pertencente à Unidade Acadêmica de Engenharia Agrícola (UAEAg), da Universidade Federal de Campina Grande - UFCG, Campina Grande - PB, cujas coordenadas geográficas são $7^{\circ} 15^{\prime}$ $18^{\prime \prime}$ de latitude Sul, $35^{\circ} 52$ ' $28^{\prime \prime}$ de longitude Ouest e altitude média de de $550 \mathrm{~m}$. O clima da região, conforme a classificação climática de Köeppen, adaptada ao Brasil, é do tipo As, tropical, com chuvas de inverno e verão seco. $\mathrm{O}$ local apresenta temperaturas médias máximas de $33{ }^{\circ} \mathrm{C}$ nos dias mais quentes de verão e $28^{\circ} \mathrm{C}$ em dias de inverno; as temperaturas médias mínimas ficam em torno de $23{ }^{\circ} \mathrm{C}$ nos dias mais quentes de verão, ou $15{ }^{\circ} \mathrm{C}$ nas noites mais frias do ano, a umidade relativa do ar está entre 75 e $82 \%$ e, normalmente, o inverno começa em maio e termina em agosto (Coelho; Soncin, 1982).

Adotou-se o delineamento experimental de blocos casualizados, em esquema fatorial $4 \times 2$, sendo 4 genótipos de girassol (EMBRAPA 122/ V2000 - $G_{1}$, Sol Noturno $-G_{2}$, Sol Vermelho $-G_{3}$ e Debilis Creme $-\mathrm{G}_{4}$ ) e 2 tipos de água (águas de abastecimento $-\mathrm{A}_{1}$ e residuária tratada oriunda de esgoto doméstico $-\mathrm{A}_{2}$ ), com 3 repetições tendo 2 plantas por parcela. Cada unidade experimental foi constituída de uma planta por vaso plástico com capacidade para $10 \mathrm{~kg}$ de material de solo, pintado com tinta automotiva branca, tendo a sua base preenchida com brita de número 0 com vedação parcial dos orifícios de drenagem, buscando facilitar o preenchimento com o solo, evitando assim a perda de material e, também para facilitar a drenagem após as irrigações.

Após o preenchimento com, aproximadamente, $0,3 \mathrm{~kg}$ de brita, foram acondicionado nos vasos $5 \mathrm{~kg}$ de solo classificados como Neossolo Regolítico Distrófico, tipo franco argiloso não salino e não sódico coletado na camada superficial $(0-20 \mathrm{~cm})$, originário de uma área localizada no município de Campina Grande, distrito de São José da Mata. O material de solo coletado foi somente destorroado, homogeneizado, passado em peneira com malha 
de $5 \mathrm{~mm}$ e posto para secar ao ar; após secagem o mesmo foi caracterizado no Laboratório de Irrigação e Salinidade da Universidade Federal de Campina Grande - LIS, utilizando metodologias recomendadas por EMBRAPA (1997). Com relação às propriedades físicas, o solo apresenta porosidade total de $42,35 \%$ e capacidade de campo, ponto de murchamento permanente e água disponível, de 83,6; 22,9 e $60,7 \mathrm{~g} \mathrm{~kg}^{-1}$, respectivamente. O resultado da análise química está disponível na Tabela 1. Este volume ocupou os dois terços da parte inferior mais profunda dos vasos. Já a camada mais superficial foi homogeneizada misturada com $10 \%$, equivalente a $770 \mathrm{~g}$ de esterco bovino curtido durante 2 meses, aplicados em única parcela. O esterco foi aplicado superficialmente para facilitar a absorção dos nutrientes pelas raízes das plantas de girassol e aumentar retenção dos íons do complexo sortivo do solo, impedindo a rápida lixiviação.

Um vaso de cada tratamento foi utilizado como lisímetro de drenagem a fim de conhecer a necessidade hídrica de cada variedade de girassol estudada. No início do experimento, o solo contido nos vasos foi elevado à capacidade de campo com a respectiva água (abastecimento ou residuária); posteriormente, as plantas desses vasos eram irrigados com uma fração de lixiviação, média de $10 \%$, às 17 horas do dia anterior à irrigação e os volumes drenados foram coletados às 7 horas, calculando o consumo hídrico da planta no período. Esse volume foi adicionado antes na irrigação; conforme metodologia utilizada por Medeiros et al. (2007).

A irrigação foi iniciada aos 7 dias após a semeadura (DAS), com um turno de rega de 2 dias, determinando, a cada irrigação, os valores de $\mathrm{pH}$ e condutividade elétrica (CE) das água de abastecimento e residuária e, coletadas amostras de $100 \mathrm{~mL}$ das águas para monitoramento da qualidade química (Tabela 2).

A água residuária utilizada na irrigação do experimento foi originária do córrego de Monte Santo, esgoto de origem doméstica próximo da área experimental, oriunda dos bairros Monte Santo e Bodocongó, localizados próximo ao perímetro do Campus. A água foi captada por meio de bomba SAP e em seguida tratada, primeiro, por sistema de wetland, e, como segundo tratamento sequencial, passou por Reator Anaeróbio de Manta de Lodo (UASB - Upflow Anaerobic Sludge Blanket). Após entrada da água, pela parte inferior do UASB, ocorreu a sua ascensão no interior da manta de bactérias, de volume calculado com base na vazão diariamente desejada. A fase final deste processo ocorreu quando a água foi descarregada através da parte superior do reator de onde caiu diretamente num reservatório de $5000 \mathrm{~L}$ de capacidade e, em seguida, foi bombeada para o reservatório de $200 \mathrm{~L}$, sendo posteriormente utilizada no experimento.

As variedades de girassol ornamental, para uso em jardim, vaso ou corte (Sol Noturno, Sol Vermelho e Debilis Creme), utilizadas no experimento, foram desenvolvida pela Empresa ISLA Sementes. Completando o quadro das variedades utilizadas no experimento, escolheu-se a variedade EMBRAPA 122/V2000, originalmente desenvolvida pela EMBRAPA para a produção de grãos, por sua precocidade podendo ser utilizada para fins ornamental por sua beleza.

Foram semeadas 5 sementes por vaso à profundidade de $3 \mathrm{~cm}$, e irrigando com $100 \mathrm{~mL}$ diariamente utilizando as respectivas águas relativas aos tratamentos, visando a aderência da semente ao solo. Foi feito o desbaste aos 10 Dias Após a Semeadura (DAS), deixando o vaso com 2 plantas, e aos 20 DAS deixando o vaso com uma única planta na qual foram realizadas todas as avaliações durante o período.

Apesar das plantas terem o potencial produtivo de serem multi-capituladas, com exceção da EMBRAPA 122/V-2000, devido à uma variação genética das sementes, foi deixado somente o capítulo apical, e, para a obtenção desta única flor no caule, praticou-se o "pinch" (beliscão), seguindo metodologia semelhante à aplicada em crisântemos de corte, retirando assim

Tabela 1. Características químicas do Neossolo Regolítico Distrófico antes do início do experimento.

\begin{tabular}{|c|c|c|c|c|c|c|c|c|c|c|c|c|c|}
\hline \multicolumn{4}{|c|}{$\begin{array}{l}\text { Complexo sortivo } \\
--c m o l c ~ k^{-1}\end{array}$} & \multicolumn{8}{|c|}{ Extrato de saturação } & \multirow{2}{*}{ pHps } & \multirow{2}{*}{$\begin{array}{c}\text { CEes } \\
\mathrm{dS} \mathrm{m}^{-1}\end{array}$} \\
\hline $\mathrm{Ca}^{2+}$ & $\mathrm{Mg}^{2+}$ & $\mathrm{Na}^{+}$ & $\mathrm{K}^{+}$ & $\mathrm{Cl}^{-}$ & $\mathrm{CO}_{3}{ }^{2-}$ & $\mathrm{HCO}_{3}^{-}$ & $\mathrm{SO}_{4}^{-}$ & $\mathrm{Ca}^{2+}$ & $\mathrm{Mg}^{2+}$ & $\mathrm{Na}^{+}$ & $\mathrm{K}^{+}$ & & \\
\hline 1,87 & 1,05 & 0,06 & 0,23 & 3,75 & - & 1,70 & - & 1,75 & 2,00 & 1,12 & 0,55 & 6,15 & 0,67 \\
\hline
\end{tabular}


os botões axilares ou laterais, evitando o gasto de energia desnecessário da planta.

As variáveis avaliadas no final do experimento, no momento individual de colheita das flores, foram: altura de haste $(\mathrm{AH})$, diâmetro de caule (DC), número de folhas (NF), diâmetro externo (DE) e interno da flor (DI) e número de pétalas (NP), nas flores quando colhidas, assim como o aparecimento de botão floral (APBOT), início de floração (IF), abertura total do botão floral (ABTOT) e durabilidade pós-colheita (DPCOLHEITA); sendo estas quatro últimas expressadas em termos de dias.

O DE foi obtido pela média das medições horizontais e verticais dos limites das pétalas; o DI foi obtido a partir da média aritmética dos limites verticais e horizontais obtidos nas flores do disco e o NP foram contadas todas as pétalas sem qualquer critério de discriminação; o APBOT foi obtido a partir da contagem dos dias da semeadura até o momento em que foi visto uma esfera ao centro do meristema apical; para o IF considerou-se o momento em que já se nota a cor da flor, na ABTOT considerou-se a contagem dos dias da semeadura até o dia em que todas as pétalas (flores do raio) se abriram inteiramente. Para a variável DPCOLHEITA foi levado em consideração o número de dias de duração da flor cortada íntegra, sem apresentação de sintomas de senescência ou ataques de pragas, estando elas armazenadas em ambiente, com temperatura ( 20 $\left.{ }^{\circ} \mathrm{C}\right)$ e umidade relativa alta $(>80 \%)$ a, com a parte inferior do caule mergulhada no volume fixo (20 $\mathrm{mL}$ ) de água destilada em copos plásticos brancos descartáveis com capacidade para $200 \mathrm{~mL}$, cobertos com folhas de papel alumínio, com orifício para a entrada do caule, vedando o resto do espaço, evitando a entrada de poeira e insetos.

Os efeitos dos fatores tipos de água e genótipos sobre a produção orgânica de flores de girassol ornamental foram avaliados mediante análise de variância (teste F) e suas médias comparadas pelo teste de Tukey a 0,05 de probabilidade. Devido à falta de normalidade dos dados da variável DC, realizou-se transformação em $\log _{10} \mathrm{X}$. Utilizou-se o software estatístico SISVAR 5.2 (Ferreira, 2003).

\section{Resultados e Discussão}

De acordo com a análise de variância, não houve efeito significativo dos fatores água de irrigação e a interação água de irrigação x genótipos de girassol ornamental para as variáveis aparecimento de botões florais, abertura total do botão floral, durabilidade pós-colheita e início de floração; entretanto, foi constatado efeitos significativo para o fator genótipos de girassol ornamental (Tabela 3).

O aparecimento dos primeiros botões florais aos 31,75 dias após a semeadura, bem como a abertura total do botão floral aos 52,17 dias após a semeadura do genótipo EMBRAPA 122 V/2000, demonstra a sua precocidade em relação aos demais genótipos estudados que não diferiram entre si; sendo registrada precocidade em torno de $15,17 \%$, ou seja, em média de aproximadamente de 9,33 dias mais precoce para a formação dos botões florais (Tabela 3).

A maior precocidade do EMBRAPA 122/V2000 pode está relacionada ao fato desse genótipo ter sido melhorado para este fim, já que visa a produção de grãos (EMBRAPA, 2007), o que não acontece com os demais, melhorado com a finalidade ornamental. Uchôa et al. (2011) também conferiram que o genótipo EMBRAPA 122 V/2000 teve um período de desenvolvimento mais curto, colocando-a em vantagem na rapidez da colheita quando comparada a outras variedades, devido à precocidade das plantas deste genótipo.

Ainda em relação à Tabela 3 , para a variável inicio de floração, o EMBRAPA 122 V/2000 (50,17 dias) mostrou-se, também, mais precoce, embora não diferindo estatisticamente do genótipo comercial Sol Noturno (57,08 dias), sendo este último não diferindo dos genótipos Sol Vermelho e Debilis Creme. Observa-se, aproximadamente, 9,5 dias de intervalo entre o IF de $G_{1}$ e a média entre $\mathrm{G}_{3}$ e $\mathrm{G}_{4}$ (que não diferiram-se entre si). De acordo com EMBRAPA (2007), com base na média adquirida de plantios convencionais na região sul do Brasil, o florescimento do EMBRAPA 122 V/2000 tem início por volta dos 53 dias após o plantio, aproximadamente três dias a mais do que a média observada neste ensaio (50,17 dias).

Com relação à durabilidade pós-colheita dos genótipos de girassóis, o Sol Noturno se destacou, mostrando-se com maior vida útil pós-corte $(9,08$ dias), uma média de aproximadamente 2,5 dias a mais em relação aos outros genótipos, que não diferiram entre si, cerca de $40 \%$ a mais em durabilidade pós-colheita (Tabela 3). Silva et al. (2008), conferiram um aumento médio de quatro dias na durabilidade de gladíolo, outra flor ornamental de corte, ao estudarem produtos químicos capazes de prolongarem o período de durabilidade desta haste cortada, em que concluíram que, até 10 dias 
após colheita, as plantas ainda foram consideradas aceitas comercialmente.

De acordo com a análise de variância para as variáveis que denotam a qualidade de flores do girassol ornamental, pode-se verificar efeito significativo na altura de planta e no diâmetro do caule apenas para o fator água de irrigação e, efeito de todos os fatores de variação estudados para as variáveis número de folhas, diâmetro externo e interno do capitulo e número de pétalas, com exceção do efeito interativo tipo de água $\mathrm{x}$ genótipo para o diâmetro externo (Tabela 4).

As plantas de girassol irrigadas com água residuária obtiveram uma altura de plantas de $16,54 \%$ maior que as plantas irrigadas com água de abastecimento; sendo esta característica de grande interesse para as flores de corte, visto que, quanto maior a altura de plantas mais amplo o espectro de opções de utilização dessa planta na ornamentação e decoração. Desse modo, quanto mais alongado for o caule do girassol maior a vantagem comercial, uma vez que existirão opções para cortes em diversas alturas. Uchôa et al. (2011), que trabalharam com diferentes genótipos de girassol perceberam que a altura variou de 0,89 a $0,96 \mathrm{~m}$, sendo registrados as menores médias para os genótipos Agrobel 960 e EMBRAPA 122/V2000.

O diâmetro do caule teve resposta semelhante ao da altura de hastes, com as plantas irrigadas com água residuária sendo 118,46\% mais grossa em relação às plantas irrigadas com água de abastecimento (Tabela 4).

Cerqueira et al. (2008), usando água residuária tratada como fonte hídrica, observaram que a altura e o diâmetro da touceira de helicônias foram influenciadas positivamente pelo uso de água residuária tratada na irrigação.

Para o diâmetro externo das flores (DE), percebese um acréscimo significativo de 2,96 mm para as plantas irrigadas com água residuária em relação às irrigadas com água de abastecimento e, em relação aos genótipos, nota-se que os maiores DE médio foram os das plantas dos genótipos EMBRAPA 122/ V2000, Sol Noturno e Sol Vermelho não diferindo estatisticamente entre si, enquanto que, o genótipo Debilis Creme obteve o menor DE, embora não diferiu estatisticamente do Sol Vermelho. Uchôa et al. (2011), analisando a produção de girassol sob o efeito de doses de adubação potássica, concluíram que a variedade EMBRAPA 122/V2000 apresentou 
Tabela 3. Resumo da ANOVA e comparação de médias das variáveis aparecimento de botões florais (APBOT), abertura total do botão floral (ABTOT), durabilidade pós-colheita (DPCOLHEITA) e início de floração (IF) para os tipos de água e genótipos de girassóis ornamental cultivado em sistema orgânico.

\begin{tabular}{|c|c|c|c|c|c|}
\hline \multirow{2}{*}{ Causa de Variação } & \multirow{2}{*}{ GL } & \multicolumn{4}{|c|}{ Quadrados Médios } \\
\hline & & APBOT & ABTOT & DPCOLHEITA & IF \\
\hline Tipos de Água (A) & 1 & $1,26 \mathrm{~ns}$ & $84,38 \mathrm{~ns}$ & $2,34 \mathrm{~ns}$ & $86,26 \mathrm{~ns}$ \\
\hline Genótipos (G) & 3 & $151,82^{* *} *$ & $137,36^{* *}$ & $10,20 * *$ & $124,29 * *$ \\
\hline Interação A x G & 3 & $41,68 \mathrm{~ns}$ & $52,74 \mathrm{~ns}$ & $4,37 \mathrm{~ns}$ & $48,68 \mathrm{~ns}$ \\
\hline Bloco & 2 & $3,57 \mathrm{~ns}$ & $3,04 \mathrm{~ns}$ & $3,39 \mathrm{~ns}$ & $1,01 \mathrm{~ns}$ \\
\hline Resíduo & 14 & 16,03 & 19,04 & 1,42 & 20,17 \\
\hline \multirow[t]{2}{*}{$\mathrm{CV}(\%)$} & & 10,23 & 7,38 & 16,68 & 7,93 \\
\hline & & \multicolumn{4}{|c|}{ Médias ${ }^{1}$} \\
\hline \multicolumn{6}{|l|}{ Tipo de Águas } \\
\hline Abastecimento & & $38,92 \mathrm{a}$ & $61,04 \mathrm{a}$ & $6,83 a$ & $58,50 \mathrm{a}$ \\
\hline Residuária & & $39,38 \mathrm{a}$ & $57,29 \mathrm{a}$ & $7,46 \mathrm{a}$ & $54,71 \mathrm{a}$ \\
\hline \multicolumn{6}{|l|}{ Genótipos } \\
\hline EMBRAPA 122 V-2000 & & $31,75 \mathrm{a}$ & $52,17 \mathrm{a}$ & $6,25 \mathrm{a}$ & $50,17 \mathrm{a}$ \\
\hline Sol Noturno & & $40,50 \mathrm{~b}$ & $60,17 \mathrm{~b}$ & $9,08 \mathrm{~b}$ & $57,08 \mathrm{ab}$ \\
\hline Sol Vermelho & & $41,42 b$ & $62,75 b$ & $6,67 \mathrm{a}$ & $60,75 b$ \\
\hline Debilis Creme & & $42,92 b$ & $61,58 b$ & $6,58 \mathrm{a}$ & $58,42 b$ \\
\hline
\end{tabular}

** e * significativos a 1 e $5 \%$ de probabilidade, respectivamente, ${ }^{\text {ns }}$ não significativo.

${ }^{1}$ Médias seguidas de mesma letra não diferem estatisticamente entre si pelo teste de Tukey a $5 \%$ de probabilidade.

um DE de $13 \mathrm{~cm}$; valor superior ao obtido neste estudo, deve-se, provavelmente ao efeito da adubação de potássio, uma vez que este elemento é essencial para o desenvolvimento da planta. Smiderle et al. (2005), estudaram o comportamento de 6 cultivares de girassol, incluindo a EMBRAPA 122/V2000, cujos valores médios de diâmetro externo de capítulo variaram entre 15,9 e $18,6 \mathrm{~cm}$, sendo o menor diâmetro apresentado pela variedade EMBRAPA 122/V2000.

Observando os resultados do diâmetro externo e interno da flor (Tabela 4) e da durabilidade póscolheita (Tabela 3), pode-se inferir que o girassol Sol Noturno, apresentou melhores características comerciais, visto ter sido o genótipo com maior durabilidade pós-colheita e, também o de maiores diâmetros.

Com relação à interação entre os fatores, observa-se na Tabela 5 que, não há diferença significativa no número de folhas entre os tipos de água usada na irrigação para os genótipos EMBRAPA 122V/2000 e Debilis Creme, ao contrário das plantas Sol Noturno e Sol Vermelho que, quando irrigada com água residuária, o número de folhas foi estatisticamente maior do que os das plantas irrigadas com água de abastecimento. Por outro lado, não há diferença significativa no número de folhas entre os genótipos estudados quando se utiliza água de abastecimento para a irrigação das plantas; já com o uso de água residuária na irrigação, os genótipos Sol Noturno e Vermelho obtiveram maiores médias de NF, diferindo significativamente dos genótipos EMBRAPA 122/V 2000 e Debilis Creme. Ao contrário do encontrado no presente estudo, Rebouças et al. (2010) notaram, ao avaliar o crescimento do feijão caupi irrigado com água residuária de esgoto doméstico tratado, que a variável número de folhas foi significativamente maior quando se utilizou água de abastecimento.

Analisando o efeito do tipo de água de irrigação dentro de cada genótipo isolado, observou-se que, houve acréscimo no diâmetro interno da flor das plantas irrigadas com água residuária em relação a de abastecimento para todos os genótipos, exceto o Debilis Creme. Por exemplo, para o EMBRAPA $122 / \mathrm{V} 2000$ foi registrado um incremento de $1,78 \mathrm{~mm}$ no valor do diâmetro interno do capítulo quando se irrigou as plantas com água residuária; já para o Sol Noturno, o incremento foi ainda maior $(2,73 \mathrm{~mm})$.

Analisando-se o efeito dos genótipos dentro de cada tipo de água, constatou-se que, não houve diferença estatística no diâmetro interno da flor 
Tabela 4. Resumo da ANOVA e comparação de médias das variáveis para altura de haste (AH), diâmetro de caule (DC), número de folhas (NF), diâmetro externo da flor (DE), diâmetro interno da flor (DI) e número de pétalas (NP) para os tipos de água e genótipos de girassol ornamental cultivado em sistema orgânico.

\begin{tabular}{|c|c|c|c|c|c|c|c|}
\hline \multirow{2}{*}{ Causa de Variação } & \multirow{2}{*}{ GL } & \multicolumn{6}{|c|}{ Quadrados Médio } \\
\hline & & $\mathrm{AH}$ & $\mathrm{DC}^{(1)}$ & $\mathrm{NF}$ & $\mathrm{DE}$ & DI & NP \\
\hline Tipos de Água (A) & 1 & $2061,73 * *$ & $0,42 * *$ & $165,38 * *$ & $52,90 * *$ & $20,41 * *$ & $894,26^{* *}$ \\
\hline Genótipos (G) & 3 & $284,57 \mathrm{~ns}$ & $0,05 \mathrm{~ns}$ & $25,40 * *$ & $6,51 * *$ & $3,06 * *$ & $128,54 * *$ \\
\hline Interação A x G & 3 & $449,53 \mathrm{~ns}$ & $0,04 \mathrm{~ns}$ & $18,13 * *$ & $2,93 \mathrm{~ns}$ & $1,22 * *$ & $83,09 * *$ \\
\hline Bloco & 2 & $246,26 \mathrm{~ns}$ & $0,02 \mathrm{~ns}$ & $0,32 \mathrm{~ns}$ & $0,03 \mathrm{~ns}$ & $0,03 \mathrm{~ns}$ & $9,70 \mathrm{~ns}$ \\
\hline Resíduo & 14 & 239,16 & 0,02 & 3,06 & 1,28 & 0,2 & 7,46 \\
\hline \multirow[t]{2}{*}{$\mathrm{CV}(\%)$} & & 15,04 & 14,91 & 9,19 & 11,68 & 13,17 & 11,2 \\
\hline & & \multicolumn{6}{|c|}{ Médias $^{2}$} \\
\hline Tipo de Águas & & $\mathrm{cm}$ & $\mathrm{Mm}$ & unidade & $\mathrm{mm}$ & $\mathrm{mm}$ & unidade \\
\hline Abastecimento (A1) & & $93,53 b$ & $6,12 b$ & $16,42 b$ & $8,19 b$ & $2,46 b$ & $18,29 b$ \\
\hline Residuária (A2) & & $112,07 \mathrm{a}$ & $13,37 \mathrm{a}$ & $21,67 \mathrm{a}$ & $11,15 \mathrm{a}$ & $4,31 \mathrm{a}$ & $30,50 \mathrm{a}$ \\
\hline \multicolumn{8}{|l|}{ Genótipos } \\
\hline EMBRAPA 122 V-2000 & & $94,41 \mathrm{a}$ & $6,94 \mathrm{a}$ & $16,33 b$ & $10,50 \mathrm{a}$ & $3,55 \mathrm{a}$ & $21,58 b$ \\
\hline Sol Noturno & & $100,07 \mathrm{a}$ & $8,32 \mathrm{a}$ & $21,17 \mathrm{a}$ & $10,43 \mathrm{a}$ & $4,03 \mathrm{a}$ & $29,83 a$ \\
\hline Sol Vermelho & & $109,53 \mathrm{a}$ & $15,78 \mathrm{a}$ & $19,92 \mathrm{a}$ & $9,48 \mathrm{ab}$ & $3,60 \mathrm{a}$ & $26,50 \mathrm{a}$ \\
\hline Debilis Creme & & $107,18 \mathrm{a}$ & $7,94 \mathrm{a}$ & $18,75 \mathrm{ab}$ & $8,27 \mathrm{~b}$ & $2,36 b$ & $19,67 b$ \\
\hline
\end{tabular}

** e* significativos a 1 e $5 \%$ de probabilidade, respectivamente, ${ }^{\text {ns }}$ não significativo.

${ }^{2}$ Médias seguidas de mesma letra não diferem estatisticamente entre si pelo teste de Tukey a $5 \%$ de probabilidade. ${ }^{1}$ Dados transformados em $\log _{10} \mathrm{X}$ para analise estáticas .

Tabela 5. Desdobramento da interação entre os fatores tipo de água x genótipo para as variáveis Número de Folhas (NF), Diâmetro Interno de Capítulo (DI) e Número de Pétalas (NP) dos genótipos de girassol ornamental cultivado em sistema orgânico.

\begin{tabular}{|c|c|c|c|c|}
\hline \multirow[b]{2}{*}{ Tipo de água } & \multicolumn{4}{|c|}{ Genótipo } \\
\hline & $\begin{array}{c}\text { EMBRAPA } 122 \\
\text { V } 2000\end{array}$ & $\begin{array}{c}\text { Sol } \\
\text { Noturno }\end{array}$ & $\begin{array}{c}\text { Sol } \\
\text { Vermelho }\end{array}$ & $\begin{array}{l}\text { Debilis } \\
\text { Creme }\end{array}$ \\
\hline & \multicolumn{4}{|c|}{ Número de folhas } \\
\hline Abastecimento & $15,33 \mathrm{aA}$ & $17,17 \mathrm{bA}$ & $15,67 \mathrm{bA}$ & $17,50 \mathrm{aA}$ \\
\hline \multirow[t]{2}{*}{ Residuária } & $17,33 \mathrm{aB}$ & $25,17 \mathrm{aA}$ & $24,17 \mathrm{aA}$ & $20,00 \mathrm{aB}$ \\
\hline & \multicolumn{4}{|c|}{ Diâmetro interno } \\
\hline Abastecimento & $2,66 \mathrm{bA}$ & $2,66 \mathrm{bA}$ & $2,48 \mathrm{bA}$ & $2,05 \mathrm{aA}$ \\
\hline \multirow[t]{2}{*}{ Residuária } & $4,44 \mathrm{aA}$ & $5,39 \mathrm{aA}$ & $4,72 \mathrm{aA}$ & $2,68 \mathrm{aB}$ \\
\hline & \multicolumn{4}{|c|}{ Número de pétalas } \\
\hline Abastecimento & $14,67 \mathrm{bA}$ & $19,67 \mathrm{bA}$ & $20,33 \mathrm{bA}$ & $18,50 \mathrm{aA}$ \\
\hline Residuária & $28,50 \mathrm{aB}$ & $40,00 \mathrm{aA}$ & $32,67 \mathrm{aB}$ & $20,83 \mathrm{aC}$ \\
\hline
\end{tabular}

Médias seguidas de mesma letra minúscula não diferem estatisticamente entre si na vertical e com letras maiúsculas na horizontal.

entre os genótipos quando irrigados com água de abastecimento; já ao se utilizar a água residuária, o genótipo Debilis Creme se diferenciou dos demais, reduzindo seu diâmetro interno em 1,67; 2,01 e 1,76 mm em relação aos genótipos EMBRAPA 122V/2000, Sol Noturno e Sol Vermelho, respectivamente, os quais não diferem entre si.
Ainda em relação à interação entre os fatores, observa-se que para a variável número de pétalas, ocorreu diferença entre os tipos de água para os genótipos EMBRAPA 122V/2000, Sol Noturno e Sol Vermelho, sendo registrados um aumento de 13,$83 ; 20,33$ e 12,34 pétalas por botão floral para as plantas de girassol irrigadas com água residuária 
em comparação com as que foram irrigadas com água de abastecimento (Tabela 5). Observa-se que tanto para número de pétalas como para diâmetro interno da flor, a água residuária apresentou melhores resultados do que a água de abastecimento para a maioria das variedades talvez isso seja uma consequência do suprimento adicional dos nutrientes, sobretudo micronutrientes contidos na água residuária (Tabela 2). Quanto às diferenças entre os genótipos dentro de cada tipo de água, nota-se que a água de abastecimento, usada na irrigação, não provocou efeito sob o NP entre eles; já ao se irrigar com água residuária, o genótipo Sol Noturno produziu mais pétalas que os demais (40 pétalas por botão), seguido dos girassóis EMBRAPA 122/V2000 e a Sol Vermelho que não diferiram entre si $(28,50 \mathrm{e}$ 32,67 pétalas por botão floral) e, por fim, o Debilis Creme apresentou menor número de pétalas $(20,83$ pétalas por botão floral), diferindo estatisticamente dos demais.

Souza et al. (2010), avaliando a utilização de água residuária e de adubação orgânica no cultivo do girassol, em experimento desenvolvido nas mesmas condições que o presente estudo, observaram resultados semelhantes para o número de pétalas ao encontrado neste estudo.

Mediante o discutido, pode-se inferir que na qualidade do conjunto floral, expressa pelas variáveis de produção: diâmetro externo, diâmetro interno e número de pétalas, a variedade Debilis Creme se apresentou inferior às demais.

Medeiros et al. (2007) estudando viabilidade de utilização de água residuária no cultivo de gérberas, não constataram efeito significativo para a variável diâmetro de capítulo, diferentemente ao encontrado neste experimento com a cultura do girassol pois todas as variáveis apresentaram efeitos significativos mostrando que a água residuária infleuenciou-as positivamente, talvez devido a maior exigência nutricional do girassol comparado com as gérberas.

\section{Conclusão}

O uso de água residuária proporcionou a melhor qualidade comercial e durabilidade pós-colheita dos genótipos de girassol ornamental em sistema orgânico de cultivo.

A variedade Sol Noturno se destacou com maior durabilidade pós-corte dentre os genótipos estudados, enquanto a Debilis Creme apresentou os menores índices de qualidade de flores para corte.

\section{Agradecimentos}

Ao CNPq pela concessão da bolsa de doutorado do primeiro autor e auxilio financeiro da pesquisa.

\section{Literatura Citada}

Bongers, F.J.

1995 A economia das flores. Revista Agroanalysis, Rio de Janeiro, v. 15, n. 9, pp. 1-4.

Cerqueira, L.L.; Fadigas, F.S.; Pereira, F.A.; Gloaguen, V.G.; Costa, J.A.

2008 Desenvolvimento de Heliconia psittacorum e Gladiolus hortulanus irrigados com águas residuárias tratadas. Revista Brasileira de Engenharia Agrícola e Ambiental, Campina Grande, v. 12, n. 6, pp. 606-613.

Coelho, M.A.; Soncin, N.B.

1982 Geografia do Brasil. São Paulo: Moderna. 368 p.

EMBRAPA

1997 Empresa Brasileira de Pesquisa Agropecuária. Manual e métodos de análise de solo. 2 ed. Rio de Janeiro. Centro Nacional de Pesquisa de Solos. 247 p.

EMBRAPA

2007 Empresa Brasileira de Pesquisa Agropecuária. Catálogo de produtos e serviços. Net. Disponível em: http://www.catalogosnt. cnptia.embrapa.br/catalogo20/catalogodeprodutoseservicos/ arvore/CONT000f6jiw97r02wx5af000lwo7x8il6nj.html. Acessado em: 24 de Fevereiro.
Ferreira, D.F.

2003 Programa Sisvar - programa de análises estatísticas. Lavras: UFLA.

Lins, S.R.O.; Coelho, R.S.B.

2004 Ocorrência de doenças em plantas ornamentais tropicais no Estado de Pernambuco. Revista Fitopatologia Brasileira, Brasília, v. 29, pp. 332-335.

Mäder, P.; Fliessbach, A.; Dubois, D.; Gunst, L.; Fried, P.; Niggli, U.

2002 Soil fertility and biodiversity in organic farming. Science, Washington, v. 296, pp. 1694-1697.

Medeiros, S.S.; Soares, F.A.L.; Gheyi, H.R.; Fernandes, P.D. 2007 Uso de água residuária de origem urbana no cultivo de gérbera: efeito nos componentes de produção. Engenharia Agrícola, Jaboticabal, v. 27, n. 2, pp. 569-578.

Polat, E.; Demir, H.; Erler, F.

2010 Yield and quality criteria in organically and conventionally grown tomatoes in Turkey. Scientia Agrícola, Piracicaba, v. 67, n. 4 , pp. $424-429$. 
Rebouças, J.R.L.; Dias, N.S.; Gonzaga, M.I.S.; Gheyi, H.R.; Sousa Neto, O.N.

2010 Crescimento do feijão-caupi irrigado com água residuária de esgoto doméstico tratado. Revista Caatinga, Mossoró, v. 23, n. 1, pp. 97-102.

Schoellhorn, R.; Emino, E.; Alvarez, E.

2003 Specialty cut flower production guides for Florida: Sunflower. Gainesville: University of Florida, IFAS Extension, $3 \mathrm{p}$.

Silva, L.R.; Oliveira, M.D. de M.; Silva, S. de M.

2008 Manejo pós-colheita de hastes florais de gladíolos (Gladiolus grandiflorus L.). Acta Agronômica, Palmira, v. 57, n. 2, pp. 128-135.
Smiderle, O.J.; Mourão Júnior, M.; Gianluppi, D. 2005 Avaliação de cultivares de girassol em savana de Roraima. Acta Amazônica, Manaus, v. 35, n. 03, pp. 331-336.

Souza, R.M.; Nobre, R.G.; Gheyi, H.R.; Dias, N.S.; Soares, F.A.L. 2010 Utilização de água residuária e de adubação orgânica no cultivo do girassol. Revista Caatinga, Mossoró, v. 23, n. 2, pp. 125-133.

Uchôa, S.C.P.; Ivanoff, M.E.A.; Alves, J.M.A; Sediyama, T.; Martins, S.A.

2011 Adubação de potássio em cobertura nos componentes de produção em cultivares de girassol. Revista Ciência Agronômica, Fortaleza, v. 41, n. 1, pp. 8-15. 
